\section{CASE OF \\ CANCEROUS STRICTURE OF THE RECTUM, PRODUCING OBSTRUCTION, SUCCESS- FULLY RELIEVED BY COLOTOMY.}

\author{
BY T. B. CURLING, F.R.S.
}

MR. C—, aged forty-eight, a tall, hale-looking man, a market-gardener, was brought to me by Mr. C. Thompson, of Westerham, on March 13th, 1868, on account of obstruction in the lower bowel. It appeared that he had been subject to relared bowels for three or four years, and that he had not passed a formed motion during that period. He had voided bloody mucus occasionally. His bowels having been confined for several days, he was induced to take some black draughts and large doses of castor-oil. They produced no evacuations, but caused romiting, and he then sent for Mr. Thompson, who allayed the sickness with opium. He passed afterwards a very small quantity of liquid feculent matter. When I saw him, obstruction had existed for twelve days. His tongue was loaded, and he had lost all appetite. His pulse was tolerably firm. His abdomen was enlarged, but not extremely distended, and there was no pain on pressure in any part. On digital examination of the rectum, I detected, as high up as the finger could reach, a mass of induration, with a close irregular aperture, indicating a cancerous stricture. I had no hesitation in recommending colotomy to relieve the obstruction, and to retard the progress of the cancerous disease. On the 15th, I went down to Westerham, and performed the operation. Since the 13th, about half a pint of liquid feculent matter had escaped from the rectum, but the distension of the abdomen was increased. Chloroform was given, and the colon was found without difficulty. Not an ounce of blood was lost in the operation. Liquid feculent matter passed freely from the opening in the colon in the course of the day.

I did not see this patient again, but received reports of his subsequent progress from Mir. Thompson. In a letter dated March 10th, 1869, more than a year afterwards, he states: "The colotomy has answered its purpose admirably in Mr. C__'s case. There has been no trouble in getting free evacuation of the bowel, and matters have been so well managed that really there has been little or no unpleasantness. He has worn generally a pad-a piece of sponge covered with oil silk,-or a large bone nipple shield immediately over the false anus, covered with a small square of spongio-piline, slightly wetted with carbolic-acid lotion, the whole being kept in place by a stout belt. The bowels have generally emptied themselves once a day, and the rest of the time there has been no inconvenience. He has suffered a good deal from tenesmus, and discharges of blood-stained mucus from the rectum; but I control this, and the pains which at times are severe all over the pelvic region, with suppositories of opium. He is now using about four grains a day. He is getting slowly weaker, but his life is very tolerable."

Our patient lived till the 12th of August, having survived the operation seventeen months. Mr. Thompson writes thus:-

"He had been gradually sinking for some months, and the end was caused by the sudden loss of a considerable quantity of blood from the rectum. He suffered very much latterly from attacks of violent neuralgic pains, with spasms of the muscles of both thighs, and occasionally had attacks of convulsire spasms of the muscles of the arms and neck. To relieve these, I was accustomed to give morphia subcutaneously, and at last the large dose of three grains and a half was thus administered twice daily without producing narcotism. Besides this, the rectum was so irritable that he had four grains of opium introduced in suppositories twice daily, and he was most uncomfortable if they were omitted."

Mr. Thompson examined the body, and noticed how little it was emaciated. He found the shrunken colon healthy for about four inckes below the false anus. He could not get the tip of his finger below the sigmoid flexure. A mass of hard cancer blocked it completely, and seemed to have obliterated the several structures. It invaded the posterior wall of the pelvis, sacral plexus, \&e., accounting for the pains the patient had suffered. The other viscera appeared healthy, but the examination was hurried. A large tumour had formed at the right elbow, which seemed to be a deposit of soft cancer in the upper part of the radius, distending the bone.

This case is deserving of record, as showing the great advantage of colotomy in cancer of the rectum. The patient was not only rescued from impending cieath from obstruction, and survived the operation seventeen months, but, as Mr. Thompson's reports show, he lived in tolerable comfort for twelve months, when the advance of the disease gave rise to considerable suffering, which required unusually large doses of morphia for its relief. It was fortunate for the patient that colotomy was required at a comparatively early period of the disease ; for it is only when the operation is performed early that we can hope to retard the progress of cancer, and to prevent the frequent painful defecation which is generally so distressing in these cases.

In a recent discussion at the Clinical Society, Mr. Erichsen is reported to have said " that the great relief afforded by colotomy in cancer had been demonstrated in Paris as elsewhere." The credit of having first suggested the operation to retard the progress of scirrhous disease of the rectum and large intestine, and to prolong life, is justly due to Amussat; but his memoirs on the operation, which I presume include all the cases in which he had performed it, contain no case in which it was done without the existence of obstruction-merely to relieve the sufferings of cancer; and what is remarkable, the French surgeons do not seem to have appreciated the advantages of the operation for this purpose. I know of no published case in which colotomy has been performed in Paris except to relieve obstruction.

Grosvenor-street, Dec. 1869.

\section{FURROWS ON THE NAILS AFTER ILLNESS.}

\section{BY SAMUEL, WILKS, M.D., PHYSICIAN TO GUX'S HOSPITAL.}

IN a number of THE LANCET for January of the present year I gave a brief account of certain markings on the nails, observable a short period after illness, indicating that at this time the nutritive processes must have been in abeyance. I stated that this indentation on the nail was so common, and was so readily observable by patients themselves, that the absence of all mention of it by systematic writers must be considered most remarkable. Subsequently, Mr. Erasmus Wilson stated that in a later edition of his work he had quoted from an article by M. Beau, which appeared in vol. ii. of the Archives Générales de Médecine, but Mr. Wilson says nothing to confirm the author's observations. In this essay, which appeared many years ago, M. Bear appears to have carefully studied the subject, and describes how, after a severe illness, a horizontal notch or mark appears on the nails; and he proceeds to state how, by its position, we may be enabled to fix the date of the illness; for the nails of the fingers grow a millimetre a week, or one whole length in the space of five months. The nails of the great toes take four times this period. Thus, if a marking be found on the nails situated midway between the root and the extremity, the illness must have occurred about three months previously. From my own observations, I should say that the descriptions given by M. Beau are tolerably correct.

In confirmation of the statement which I made in $\mathrm{my}$ former paper to the effect that although no account of the subject was to be found in books on general medicine, or on cutaneous diseases, yet that I believed such a striking fact as markings on the nail after an illness must be well known, I may say that that paper brought me several communications of great interest, not only substantiating the statements therein made, but indicating that the subject was one worthy of further investigation. I may state, too, that my later experience has shown how very commonly this marking of the nails is met with after disorders of various kinds, and that illnesses of a not very definite character, but which eause great prostration, will more readily 
leave a trace of their existence than those local affections of organs which appear at the time much move formidable. Thus I am now seeing a gentleman who had a bad attack of gout a short time ago, and a distinct mark is visible on his nails, corresponding to the time of the illness. In another gentleman there exists a mark on his nails at about oneeighth part distant from the root; he had an attack of acute rhormatism about six weeks ago. I have also lately seen another patient with these markings well formed after a severe attack of diphtheria.

Amongst the many interesting communications which have come to hand, I may mention one from Sir Thomas Watson, in which he informs me that he had several years ago an interesting conversation with Dr. Maclean, of the Colchester Hospital, on this subject; the latter gentleman having observed transverse depressions on men's nails in consequence, as be thought, of temporary starvation or arrest of nutrition of the tissues during a bygone acute disease, and these he called "hunger traces." "Dr. Maclean had also noticed similar furrows on the hoofs of horses, and indentations or traces on the wings and tail feathers of domestic fowls and of wild birds living in captivity under similar conditions. Mr. Salter also informs me that some illnesses leave indelible traces on the teeth; and, if I have not misunderstood him, he has known a severe attack of whooping cough in childhood leave its traces on the teeth for ever. Dr. Mackaye, of Ardgay, informs me that he was much interested in the subject many years ago, not only in reference to the nails, but as to the changes which the hair undergoes; and he was led more especially to the investigation by the allusions made to the subject by Professor Alison in his lectures at the Edinburgh University. Dr. Washbourn, of Gloucester, also sent me a very interesting account of his own case, which was one of a most severe choleraic attack, accompanied by an alarming prostration and a sensation of icy coldness at the epigastrium; this was succeeded on his recovery by markings on all his nails, which he watched creeping on to the edge, when they finally disappeared.

There seems, then, to be sufficient facts to prove that during a severe illness a partial cessation of the nutritive processes takes place, as shown by the markings on the nails, by the falling off of the hair, or by the furrows on the teeth. Further observation may show in what affections these changes are more likely to occur, and thus may afford some indication of the amount of prostration which the system has undergone. It is remarkable that the first case in which I observed the nail-marks was one identical with that of Dr. Washbourn, one where a sudden and almost fatal prostration succeeded to a choleraic attack. The whole subject is suggestive of a wide field of physiological and pathological inquiry; at present it remains rather within the range of clinical study.

Grosvenor-street, W., Dec. 1869.

\section{ON THE}

\section{EFFECTS OF THE ANTISEPTIC SYSTEM OF TREATMENT UPON THE SALUBRITY} OF A SURGICAL HOSPITAL.

\section{BY JOSEPH LISTER, F.R.S.}

PROFESSOR OF CLINICAI SLRGERY IN THE UNIVERSITY OF EDINBCRGH.

THE antiseptic system of treatment has now been in operation sufficiently long to enable us to form a fair estimate of its influence upon the salubrity of an hospital.

Its effects upon the wards lately under my care in the Glasgow Royal Infirmary were in the highest degree beneficial, converting them from some of the most unhealthy in the kingdom into models of healthiness. The interests of the public demand that this striking change should be made generally known; and in order to do justice to the subject, it is necessary, in the first place, to allude shortly to the position and circumstances of the wards.

Each of the four surgeons of the infirmary had charge of three large wards, two male and one female, besides several small ones for special cases. Of these, the most important were the male accident ward and that for female patients, the former containing the chief operation cases as well as those of injury. The third main ward of each surgeon was devoted to chronic male cases, and was in the old infirmary building; but the other two were in the "New Surgical Hospital," erected nine years ago. This consists of four stories above a basement, each floor containing two large wards communicating with a central staircase, besides several smaller apartments. The wards are spacious and lofty, and in the centre of each are two open fireplaces, in a column which runs straight up to the roof, conveying the chimneys of all the floors, and also collateral ventilating shafts, which are warmed by the chimneys that accompany them, and, communicating with various apertures in the ceilings, form excellent means of carrying off the vitiated atmosphere, while fresh air is amply supplied by nume rous windows at both sides, the beds being placed in the intervals between them, at a considerable distance from each other. Except the serious defect that the waterclosets in many cases open directly into the wards, the system of construction seemed all that could be desired.

But, to the great disappointment of all concerned, this noble structure proved extremely unhealthy. Pyæmia, erysipelas, and hospital gangrene soon showed themselves, affecting, on the average, most severely those parts of the building nearest to the ground, * including my male accident ward, which was one of those on the ground-floor; while my female ward was on the floor immediately above. For several years I had the opportunity of making an observation of considerable, though melancholy, interestviz., that in my accident ward, when all or nearly all the beds contained patients with open soies, the diseases which result from hospital atmosphere were sure to be present in an aggravated form; whereas, when a large proportion of the cases had no external wound, the evils in question were greatly mitigated or entirely absent. This appeared striking evidence that the emanations from foul discharges, as distinguished from the mere congregation of several human beings in the same apartment, constitute the great source of mischief in a surgical hospital. Hence I came to regard simple fractures, though almost destitute of professional interest to myself and of little value for clinical instruction, as the greatest blessings; because, having no external wound, they diminished the proportion of contaminating cases. At this period I was engaged in a perpetual contest with the managing body, who, anxious to provide hospital accommodation for the increasing population of Glasgow, for which the infirmary was by no means adequate, were disposed to introduce additional beds beyond those contemplated in the original construction. It is, I believe, fairly attributable to the firmness of my resistance in this matter that, though my patients suffered from the evils alluded to in a way that was sickening and often heartrending, so as to make me sometimes feel it a questionable privilege to be connected with the institution, yet none of my wards ever assumed the frightful condition which sometimes showed itself in other parts of the building, making it necessary to shut them up entirely for a time. A crisis of this kind occurred rather more than two years ago in the other male accident ward on the ground-floor, separated from mine merely by a passage $12 \mathrm{ft}$. broad; where the mortality became so excessive as to lead, not only to closing the ward, but to an inves tigation into the cause of the evil, which was presumed to be some foul drain. An excavation made with this view disclosed a state of things which seemed to explain sufficiently the unhealthiness that had so long remained a mystery. A few inches below the surface of the ground, on a level with the floors of the two lowest male accident wards, with only the basement area, $4 \mathrm{ft}$. wide, intervening, was found the uppermost tier of a multitude of coffins, which had been placed there at the time of the cholera epidemic of 1849 , the corpses having undergone so little change in the interval that the clothes they had on at the time of their hurried burial were plainly distinguishable. The wonder now was, not that these wards upon the ground-floor had been unhealthy, but that they had not been absolutely pestilential. Yet at the very time when this shocking disclosure was being made, I was able to state, in an address which I delivered to the meeting of the British Medical

* Statistics collected by desire of the managers established the fact that the ground-floor wards were, on the arerage, most liable to pyæmia, whoever might be the surgeon in charge; and that those on the floor immediately above came next in this respect. 